\title{
Comunicación digital y líneas de fractura en el paradigma de la agenda setting
}

\section{Guillermo López García}

Profesor de Periodismo.

Universidad de Valencia

Resumen:

Este artículo propone realizar una prospectiva que arroje alguna luz sobre las modificaciones que puede sufrir la teoría de la Agenda Setting, e incluso, eventualmente, su superación, por efecto del desarrollo de los sistemas de comunicación digital. La hipótesis de la que partimos es la de que, si bien la multiplicación y diversificación de medios de comunicación provocada por las tecnologías digitales no tiene por qué haber supuesto, hasta el momento, una diversificación de similar calado en lo que concierne a los temas de interés informativo sancionados por los medios, sí implica un notorio aumento del pluralismo en lo que se refiere a las interpretaciones y opiniones ofrecidas por los distintos medios en torno a la actualidad, lo que a su vez desarrollaría ciertas líneas de fractura en el paradigma de la Agenda Setting.

Palabras clave:

Comunicación digital, comunicación interpersonal,teoría de la agenda, medios de comunicación de masas, pluralismo informativo.

\section{Abstract:}

This article proposes a prospective about the main modifications caused by the digital communication technologies in the Agenda Setting paradigm. Our hypothesis is that, although mass media multiplication and diversification caused by digital technologies may not have caused a comparable diversification in which it concerns to mass media news selection routines, it may develop an important increase of pluralism at the interpretations and opinions offered by different media related to actual events, which would also imply some fracture lines in the Agenda Setting paradigm. 


\section{Keywords:}

Digital communication, interpersonal communication, agenda setting, mass media, informative pluralism.

\section{Introducción}

El desarrollo de las tecnologías digitales en los últimos diez años ha provocado una multiplicación exponencial del número de medios de comunicación a los que tiene acceso el ciudadano. Frente a un ecosistema mediático anterior caracterizado por un reducido número de medios de comunicación, fuertemente jerarquizados, y dirigidos a una audiencia de masas fundamentalmente pasiva, la comunicación digital ha posibilitado un aumento de los medios de comunicación disponibles para el público, tanto en lo que concierne al plano cuantitativo como al cualitativo:

- Cuantitativamente: si el público consumidor de medios de comunicación estaba acostumbrado a un número reducido de publicaciones impresas, emisoras de radio y cadenas de televisión, en el contexto actual el panorama resulta mucho más fecundo: junto a los diarios de referencia tradicionales se ha producido una auténtica explosión de publicaciones de carácter gratuito, por ahora circunscritas, en su difusión, a los grandes centros poblacionales; junto a las cadenas de televisión generalistas, las plataformas de televisión por satélite y cable, además de la multiplicación de todo tipo de emisoras locales, han provocado un aumento considerable de la oferta; y junto a los medios de comunicación tradicionales ha aparecido un nuevo soporte, extendido a través de redes digitales, del cual la red Internet es su principal exponente, donde la oferta mediática tiende al infinito.

- Cualitativamente: los medios de comunicación tradicionales tendían a seguir unas reglas de producción y presentación de noticias más o menos estandarizadas, fuera de las cuales resultaba muy complicado para el público hacerse con un abanico de informaciones suficientemente plural y, sobre todo, fiable. Sin embargo, la aparición de las tecnologías digitales, al abaratar considerablemente las condiciones de producción de informaciones, posibilita que el público recurra a fuentes de información cada vez más variadas, dispersas y especializadas: junto a las televisiones generalistas aparecen multitud de canales de televisión temática, las publicaciones impresas de referencia se ven complementadas por infinidad de medios, muchas veces ajenos a los flujos de la comunicación de masas, a través de Internet, y el público pasivo característico del ecosistema mediático tradicional se ve paulatinamente sustituido por un público policonsumidor de medios que toma parte activa en la selección de informaciones, e incluso en la generación de las mismas ${ }^{1}$.

\footnotetext{
${ }^{1}$ Como señala Francisco Javier Valiente: “Si con los mass media la comunicación del saber se realizaba de forma jerárquica y unidireccional, con el desarrollo de las nuevas tecnologías de comunicación en red (...) la comunicación del saber está abierta a todos los miembros. Internet, y las otras formas de comunicación online, pueden servir para crear nuevos espacios de comunicación, sin sustituir a otros y sin priorizar la importancia del medio". (2004: 142)
} 
Estas novedades podrían suponer un incipiente cambio de paradigma en lo que concierne a los efectos de los medios de comunicación sobre el público. Nos referimos, en concreto, a la teoría de la Agenda Setting, que con diversas variantes y evoluciones a lo largo de los años, en particular los estudios relativos al "segundo nivel" y la teoría del framing (Igartua y Humanes, 2004: 256), continúa basándose en la idea de que los medios de comunicación de masas son poderosos por indicar al público no qué pensar, sino sobre qué pensar, a propósito de los asuntos de actualidad (Igartua y Humanes, 2004: 244-245).

Sin embargo, la Teoría de la Agenda Setting se fundamenta en dos parámetros que a la vista de la situación descrita pueden sufrir considerables variaciones: por un lado, la idea de que el público se basa casi exclusivamente en las fuentes de información proporcionadas por los medios de comunicación de masas para configurar una realidad cognoscible; y por otro, que el sistema de medios de comunicación de masas se caracteriza por la existencia de unos pocos medios de comunicación, fuertemente jerarquizados y unidireccionales, que concentran audiencias masivas y transmiten unos contenidos periodísticos estandarizados tanto en el fondo (los temas a los que se otorga relevancia) como en la forma (los criterios periodísticos de elaboración de informaciones).

\section{Multiplicidad de medios, homogeneidad de fuentes}

Con el fin de observar en qué medida la multiplicación de medios de comunicación, posibilitada por las tecnologías digitales, puede implicar diferencias en el tratamiento de la información de actualidad, seleccionamos un amplio elenco de fuentes informativas relativas a tres noticias, dos de ellas correspondientes a elementos noticiosos más bien secundarios en el flujo diario de la información (la llegada, el 7 de Diciembre de 2004, de Mohamed "El Egipcio" a España tras la autorización de su extradición por parte de las autoridades italianas y las críticas de diversos medios de comunicación y políticos conservadores al Secretario General de Naciones Unidas, Kofi Annan, previas a la Asamblea General de la ONU que tuvo lugar el 7 de Diciembre de 2004), y otra que podríamos considerar noticia más importante del día (la comparecencia del ex presidente del Gobierno, José María Aznar, ante la Comisión parlamentaria encargada de investigar lo relacionado con los atentados terroristas del 11 de Marzo de 2004 en Madrid, que tuvo lugar el 29 de Noviembre de 2004).

Para llevar a cabo adecuadamente este análisis era preciso contar con un amplio abanico de medios de comunicación, tanto españoles como extranjeros, que se hubieran referido a estos acontecimientos. La herramienta fundamental de análisis fue el selector de información cuantitativo News Google (news.google.es). News Google es una herramienta de búsqueda, ordenada merced a una serie de algoritmos y criterios de jerarquización en dicha búsqueda, que funciona a partir de una amplia base de datos, que en el caso de su versión española cuenta con más de 700 medios de comunicación. Su 
funcionamiento es muy similar al del buscador Google, con la salvedad de que el objeto de las búsquedas se limita a las informaciones aparecidas en los medios de comunicación que forman su base de datos ${ }^{2}$.

Ahora bien, dado que News Google se encuentra circunscrito fundamentalmente a los medios de comunicación de carácter abierto y gratuito, excluyendo en la práctica a la mayoría de los medios de pago o que requieren suscripción (muchos de los cuales, no por casualidad, son precisamente medios de referencia, esto es, los medios de mayor incidencia informativa y credibilidad), optamos por complementar los resultados de la base de datos de News Google con una recogida de datos específicos de estos medios, en concreto los diarios El País ${ }^{3}$, La Vanguardia y Clarín.

La metodología de la investigación combinaba, fundamentalmente, dos parámetros:

1. Un análisis de contenido que tenía por objeto comprobar el origen de la información. Es decir, si la información provenía de fuentes oficiales o agencias de noticias o bien era específica del medio.

2. ${ }^{\circ} \quad$ Un análisis cualitativo de aquellas noticias elaboradas, total o parcialmente, por el medio de comunicación, a fin de determinar si dichas noticias ofrecían al público información diferenciada, por arrojar datos nuevos respecto de las fuentes convencionales (agencias y fuentes oficiales) o por la elaboración e interpretación de los datos.

Este doble análisis, asumiendo que los medios de comunicación analizados (participantes, en la inmensa mayoría de los casos, de la estructura y rutinas de producción de informaciones propias de la comunicación de masas) partían de unos criterios de selección de información similares y estaban alineados con una agenda mediática en esencia común, permitiría determinar si el aumento exponencial del número de medios de comunicación a los que el público tiene acceso supone una oferta cualitativamente más atractiva que la habitual o, por el contrario, implica la subordinación a unas mismas fuentes informativas.

\footnotetext{
${ }^{2}$ Su funcionamento deriva de la combinación de dos criterios de jerarquización. Por una parte, Google prioriza las informaciones más recientes sobre una cuestión en particular (ofrecida en la selección del propio medio o enviada como respuesta a una búsqueda específica de los usuarios), ubicándolas en una posición de preeminencia sobre las publicadas anteriormente. Por otra parte, Google aplica a los medios que componen su base de datos el criterio de jerarquización PageRank, en virtud del cual los documentos de la base de datos adquieren mayor o menor relevancia en función del número de páginas web que enlazan a ese documento, criterio modificado a su vez por la importancia de las páginas que enlazan al documento en concreto. Es decir, a la hora de evaluar la importancia de un medio en concreto, Google News a) registra el número de enlaces a ese medio registrados en su base de datos; y b) modifica su posición relativa en la "clasificación" según la posición que a su vez ocupen los medios que generan los hipervínculos al medio que se está evaluando. Se trata, en consecuencia, de un criterio por una parte acumulativo (cuantos más enlaces reciba un medio, y cuanto más prestigiosos sean estos, más previsible es que las informaciones contenidas en ese medio sean relevantes y de calidad) y por otra parte igualitario (no se tienen en cuenta criterios como la procedencia del medio, por ejemplo, que podrían mejorar la "clasificación" de algunos medios digitales que son versión de medios impresos).

${ }^{3}$ El País Digital comenzó a ofrecer la mayor parte de sus contenidos gratuitamente a partir de Junio de 2005, con posterioridad a las fechas en las que se produjo la recogida de datos del estudio.
} 
Por último, con el fin de observar si se producían variaciones significativas entre los medios informativos de referencia y los demás, se procedió al análisis dividiendo las noticias en tres categorías: a) medios españoles de referencia, dentro de la cual englobamos a los siguientes medios: El País, La Vanguardia, El Mundo, ABC, La Razón, El Periódico, El Correo, La Voz de Galicia, Cadena SER, Cadena COPE, Telecinco, CNN+, Libertad Digital, que consideramos centrales en el ecosistema mediático español. b) Otros medios españoles, donde englobamos a diversas cabeceras de prensa regional y local y a un variado elenco de portales informativos y medios exclusivamente digitales. Y c) Medios extranjeros, circunscritos a los medios de habla hispana.

En el caso de la primera noticia, la llegada a España de Mohamed "El Egipcio" (7-8 de diciembre de 2004), manejamos un total de 82 noticias, provenientes de 70 medios de comunicación españoles y extranjeros. El análisis de estas noticias mostró un balance casi desolador: tan sólo en 12 de las 82 noticias la fuente era información propia del medio, y no proveniente de agencias, y únicamente en tres casos (noticias de La Vanguardia, El País y la Cadena Ser, es decir, medios de referencia) podría considerarse que se estaba ofreciendo información novedosa, diferenciada de los datos ofrecidos por las agencias de noticias. Si tenemos en cuenta que en dos de los tres casos (El País y La Vanguardia) hablamos, además, de servicios de pago o suscripción, es decir, total o parcialmente cerrados al acceso del gran público, la oferta informativa desplegada ante el público, por mucho que fuera abundante, lo era sólo por la reproducción de los mismos datos, provenientes de las mismas fuentes, en distintos soportes, no porque el abanico de informaciones resultara particularmente variado, o al menos no significativamente más que en otros medios (prensa, radio o televisión) con una oferta mediática en principio más limitada. Tan sólo cuatro de las 33 noticias analizadas dentro de la categoría "otros medios españoles" ofrecían información propia (por más que mimética de las informaciones de agencia), y en cuanto a los medios extranjeros, todos ellos, en las 27 noticias analizadas, se basaban totalmente en informaciones de agencia.

La segunda noticia, las críticas a Kofi Annan y su posterior comparecencia ante la Asamblea General de Naciones Unidas, se prolongaba varios días en el tiempo (la recogida de datos abarcó del 3 al 8 de diciembre), y tenía también una dimensión internacional mucho más evidente, con lo que cabría esperar que los medios extranjeros ofrecieran un mayor grado de implicación en el tratamiento informativo, y por lo tanto una información cualitativamente diferenciada.

En este caso se recogieron 60 noticias, provenientes de 43 medios distintos, 26 de ellos, esto es, la mayor parte, extranjeros. En 46 casos la fuente dependía de las agencias de información, y en 14 se trataba de información específicamente generada por el medio. Sólo en nueve noticias puede considerarse que la información ofrecida está claramente singularizada respecto de los datos de agencia, y nuevamente son los medios españoles de referencia los que (en 7 de los 9 casos) ofrecían una información más diferenciada, y una vez más son medios de pago o suscripción (El País, El Periódico y La 
Vanguardia) los que concentran este tipo de informaciones, con la única excepción del diario gratuito Libertad Digital, con una noticia particularmente alejada de las informaciones de agencia por la labor de interpretación que se ofrecía a los lectores. Tan sólo en dos noticias de los medios extranjeros (El diario argentino Clarín y el periódico colombiano El Tiempo) se ofrecían datos novedosos al público, o bien una interpretación y elaboración de la noticia diferenciada respecto de la norma de las agencias. En lo que concierne a la categoría "Otros medios españoles", como ya ocurriera con la anterior noticia analizada, en ningún caso se ofrecía información novedosa al público.

Naturalmente, no puede considerarse que las dos noticias analizadas hasta ahora se ubiquen en un primer plano de la actualidad, ni que susciten el máximo interés informativo entre los medios y el público. Con el objetivo de comprobar en qué medida aumentaba, por parte de los distintos medios de comunicación analizados, la generación de informaciones específicas y diferenciadas ante acontecimientos de mayor carga informativa, también se procedió a la recogida de datos relativos a la comparecencia de José María Aznar ante la Comisión parlamentaria del 11-M, que tuvo lugar el 29 de Noviembre de 2004. Dada la repercusión informativa de esta noticia, la recogida de datos abarcó un espacio de treinta días (del 12 de Noviembre al 12 de Diciembre), que tuvieran en cuenta tanto los preparativos de la comparecencia del ex presidente del Gobierno como las repercusiones posteriores, además de la información relativa a la comparecencia en sí.

En este caso, se recogieron 249 noticias pertenecientes a 69 medios distintos, subdivididos en los 13 medios de referencia (96 noticias), 22 medios extranjeros (28 noticias) y 34 pertenecientes a la categoría "Otros medios españoles" (125 noticias en total). A pesar de tratarse de una noticia de gran impacto mediático, por la importancia de las declaraciones de Aznar y por las muchas repercusiones que suscitaron, nuevamente son las agencias la fuente exclusiva de la información en una mayoría de los casos. Sin embargo, en esta ocasión el predominio de las agencias es muchísimo más ajustado. Tan sólo en 125 de las 249 noticias son las agencias la fuente de la información, por 124 noticias de información propia, correspondientes en una mayoría de los casos a la prensa española de referencia (76 noticias de información propia), pero con una presencia mucho mayor de los demás medios españoles (38 noticias de información propia) y de los medios extranjeros (10 noticias) que en las anteriores noticias analizadas, donde prácticamente no había casos en los que estos medios buscaran ofrecer una información diferenciada de las agencias.

Además, dadas las características de esta noticia, no cabe extrañar que buena parte de su información ofreciera al público datos novedosos o una importante labor interpretativa de los acontecimientos narrados, que se alejara del tono aséptico propio de las informaciones de agencia: en 74 de las 249 noticias el análisis cualitativo muestra unos contenidos que pueden considerarse novedosos y diferenciados respecto de la norma de las agencias, y aunque nuevamente es la prensa española de referencia la que ofrece mejores resultados en este capítulo, con 46 noticias, también los demás medios españoles 
(21 noticias) y la prensa extranjera (7 noticias) ofrecen en ocasiones informaciones cualitativamente diferenciadas.

Las recetas periodísticas para distinguirse cualitativamente de la competencia y ofrecer un producto singularizado no varían en el soporte digital, más allá del uso esporádico en algunos medios (como ETB, la Cadena Ser o El País) de elementos multimedia, tales como infografías dinámicas y estáticas o cortes de audio y vídeo que complementan al texto escrito, que sigue siendo el modo de expresión predominante: artículos de análisis, crónicas de los corresponsales o enviados especiales, narración de elementos anecdóticos o profundización en la información más allá de los datos ya reflejados en los teletipos de agencia (por ejemplo, entrevistas exclusivas del medio con algunos miembros de la Comisión parlamentaria y otros representantes políticos, reproducción exhaustiva, eventualmente comentada, de los contenidos de la comparecencia de Aznar, artículos de fondo, ...).

La información de agencia, que en las informaciones sobre la llegada de Mohamed "El Egipcio" representaba un $85 \%$ del total, y en lo relativo a las críticas y posterior comparecencia de Kofi Annan un $76 \%$ del conjunto de las noticias analizadas, desciende en lo relativo a la comparecencia de Aznar a poco más de un $50 \%$. En cuanto a las informaciones novedosas, que en las dos primeras noticias sólo suponían un 3,6\% (llegada de Mohamed "El Egipcio") y un 15\% (críticas y comparecencia de Annan), aquí alcanzan un respetable $29,7 \%$ del total, que además no se circunscribe exclusivamente a la prensa española de referencia, aunque siga ostentando una posición privilegiada.

Sin embargo, incluso en este caso los datos mueven a cierto pesimismo: la dependencia, en condiciones normales, de los medios de comunicación respecto de las agencias es casi total, y lo es, en particular, en los medios de carácter gratuito, muchas veces específicos de Internet, que no sólo no son una alternativa viable, desde el punto de vista de la calidad, a los grandes medios tradicionales, sino que se limitan a un ejercicio mecánico de reproducción de teletipos de agencia particularmente visible en los grandes portales generalistas, cuyos elementos de atracción del público se ubicarían más bien en el ofrecimiento de todo tipo de servicios específicos para el usuario (herramientas de comunicación interactiva pensados para crear "comunidades" asociadas al portal, como los chats o los foros de debate, correo electrónico y espacio web gratuito, acceso a Internet, etc.) que en un tratamiento diferenciado de la información de actualidad. Y esta tendencia de fondo puede verse matizada, pero en modo alguno vulnerada, ante las grandes noticias (como la comparecencia de José María Aznar) que esporádicamente atraigan la atención del público.

Es decir, a la vista de los datos, puede confirmarse una fuerte dependencia de los medios de comunicación digitales, menor en los grandes medios de referencia, respecto de las informaciones de agencia, que nos ubicaría en un ecosistema informativo caracterizado no tanto por la abundancia de fuentes de información sino por la abundancia de ubicaciones de las mismas fuentes informativas. En tal caso, el dilema estaría, en efecto, en la selección informativa, pero no sólo la efectuada por el 
medio (que es, a la vista de los datos, fuertemente mecanizada y jerarquizada por las informaciones de agencia), sino la realizada directamente por el público. Ante esta homogeneización de la información, de las fuentes y de los criterios de noticiabilidad, motivada en muchos casos más por cuestiones de desidia (Dader, 1992: 155) y falta de medios (que derivan en la mera reproducción de teletipos de agencia) que por otras razones más propiamente periodísticas en la determinación de criterios de relevancia en la agenda mediática, el poder de los medios de comunicación en la selección de los acontecimientos que conforman la actualidad acaba subsumiéndose en el poder de las agencias, y el aumento del pluralismo, desde un punto de vista cuantitativo, lo es en muchas ocasiones sólo en apariencia, puesto que no es probable que la diferencia entre consultar los mismos datos en ocho o en ochenta medios sea muy significativa.

Desde un punto de vista cualitativo, los medios de referencia son justamente aquellos que consiguen ofrecer una perspectiva singularizada de los acontecimientos de actualidad, por ofrecer más, pero sobre todo mejor, información a su público. Lamentablemente, dichos medios son en muchos casos medios de pago, y su incidencia sobre el público se ve, por tanto, muy limitada.

\section{Interpretación y opinión. Aumento del pluralismo}

Como el anterior análisis ha puesto de manifiesto, la abundancia de medios de comunicación no tiene por qué significar un mayor pluralismo informativo, dado que en la práctica los criterios de producción de informaciones no sólo siguen las pautas de la Agenda Setting en cuanto a las temáticas que se consideran relevantes, sino que también siguen, en la inmensa mayoría de los casos, las mismas fuentes y los mismos datos, presentados de la misma manera en la estructuración de las noticias, según la pauta marcada por las agencias informativas.

Podríamos estar asistiendo a lo que el sociólogo estadounidense George Ritzer (1996) denomina "mcdonalización de la sociedad", aplicada en este caso a los medios de comunicación. Recordemos cuáles son, según Ritzer, las características de los restaurantes McDonald's:

- En primer lugar, la eficacia. El sistema de los McDonald's garantiza los mejores medios disponibles, en apariencia al menos, para satisfacer nuestro apetito de la forma más rápida y eficaz posible.

- En segundo lugar, McDonald's se centra en ofrecernos un servicio en el que se nos da "más por menos", o lo máximo posible por la menor cantidad de dinero. Se trata, según Ritzer, de asimilar cantidad con calidad: mucha comida equivale a muy buena comida. Además, ahondando también en su eficacia, McDonald's garantiza que esta enorme cantidad de alimentos llega a nosotros en el menor tiempo posible, tanto en lo que se refiere a la recepción de los mismos como al consumo. Los restaurantes de comida rápida no lo son únicamente por la velocidad del servicio, sino tam- 
bién porque los productos adquiridos son de rápido consumo. McDonald's es un símbolo de la cultura de la velocidad.

- En tercer lugar, McDonald's nos ofrece aquello que es previsible, es decir, los alimentos consumidos son siempre los mismos, de sabor y cantidades idénticas, sin que importe lo más mínimo el lugar o el momento del consumo. El modelo McDonald's reduce (o elimina) la incertidumbre.

- Por último, McDonald's ejerce un férreo control sobre los individuos que forman parte de su mundo mcdonalizado, se trate de operarios o de clientes, y ese control se efectúa partiendo de la tecnología: la organización del espacio en función de la necesidad de que los clientes consuman lo antes posible y se marchen, la utilización de máquinas que garanticen que el servicio y el producto sean siempre los mismos, el adoctrinamiento de los trabajadores para que efectúen sus rutinas productivas siempre de la misma manera, ...

Estas pautas de funcionamiento de los McDonald's (eficacia, cantidad y velocidad como sinónimos de calidad, ofrecimiento de productos previsibles y control) se corresponden casi exactamente con unos criterios de generación de informaciones en los que prima la velocidad de transmisión de datos sobre su valor cualitativo, donde se confunde la buena información con la abundancia de la misma, y donde la estandarización del producto (del producto informativo, en este caso) depende cada vez en mayor medida de la fuente de las informaciones, es decir, de las agencias. Una información escasa o nulamente elaborada por unos medios de comunicación que no disponen ni de la infraestructura necesaria ni del incentivo económico para desarrollar informaciones propias y diferenciadas de la competencia, pero que también responde, en lo que respecta a la homogeneidad en los criterios periodísticos de selección de los hechos relevantes de la actualidad, a la necesidad del gran público de formar parte de una "provincia periodística” de la realidad fácilmente asumible por “idéntica y común a todos” (Dader, 1990: 131)

Junto a los criterios de producción de informaciones propios de la comunicación de masas conviven en el escenario digital multitud de formas comunicativas ajenas a los flujos de producción de las grandes empresas periodísticas, en muchos casos directamente asociadas a los mecanismos de comunicación interpersonal. Cabría preguntarse en qué medida estos medios, enormemente dispersos y por lo general poco visibles para el gran público, pueden constituirse en alternativa viable de los medios de comunicación "tradicionales" para un público que, no lo olvidemos, ya no se ve impelido en la misma medida

${ }^{4} \mathrm{O}$, como indican López-Escobar, Llamas y McCombs, “Al encaminar la agenda hacia una relativa unificación de opiniones sobre las prioridades sociales del momento, sobre los 'temas que vale la pena discutir', los medios permiten que los problemas puedan al menos ser encarados de una manera más práctica, según un determinado orden de importancia y una relativa limitación numérica, con lo que pueden concentrarse los esfuerzos de la comunidad e incluso centrarse las acciones gubernamentales o sociales. Sin un conjunto compacto de temas o asuntos por resolver, ordenado a su vez por prioridades, la funcionalidad de la sociedad como tal sería imposible". (1996: 94) 
que en un pasado no tan lejano a circunscribir su ámbito de consumo de informaciones a un estrecho abanico de grandes medios de comunicación, y probablemente por ese motivo tenga un mayor interés en configurar por sí mismo sus fuentes de explicación de la realidad que lo circunda, aunque esto suponga configurar una nueva realidad ad hoc, igualmente parcial.

$\mathrm{Y}$ aunque es cierto que los medios ajenos al flujo de la comunicación de masas no tienen, con algunas excepciones, la infraestructura y dedicación suficientes para constituirse en fuentes alternativas de información, sí parece claro que su existencia contribuye, como mínimo, a aumentar el pluralismo en dos direcciones estrechamente relacionadas con la información: la interpretación de la misma y la generación de todo tipo de opiniones y argumentaciones ligadas con los elementos noticiosos.

\subsection{Pluralismo interpretativo}

Es indudable que los grandes medios de comunicación presentan importantes diferencias de tipo ideológico en la interpretación de la realidad. Pero también lo es que dichas diferencias suelen estructurarse en torno a unos ejes más o menos reconocibles, caracterizados normalmente, en las sociedades democráticas, por la moderación; incluso en países con medios fuertemente ideologizados, como es el caso de España. Las discusiones en torno a los grandes asuntos de actualidad pueden ser vigorosas y fuertemente enconadas, pero no suelen abandonar las posiciones que definen al medio, que son las que lo hacen reconocible ante sus lectores.

Es decir, la credibilidad de un gran medio de comunicación, el valor de las opiniones que despliega ante su público, se concentra en buena medida, nuevamente, en lo que este medio tiene de previsible: el público consumidor de medios de comunicación busca en el medio unas opiniones cuyo sentido es habitualmente fácil de intuir. El público reconoce en el medio no sólo una realidad comprensible, sino una realidad interpretada de manera comprensible. Con independencia de que pongamos el acento en los efectos del medio sobre el público o en las necesidades que éste satisface en el público (esto es, en el poder del medio sobre el público o el poder del público para configurar los contenidos del medio), la relación entre ambos no abandona normalmente los cauces de la previsibilidad: se ubica en un espacio limitado por un reducido número de medios de comunicación, a los que corresponde un número reducido de posibles interpretaciones de la realidad.

Sin embargo, como hemos hecho hincapié anteriormente, el público consumidor de tecnologías digitales tiene a su disposición un número de medios de comunicación mucho mayor que el correspondiente al ecosistema mediático tradicional. Estos medios, que surgen en la mayor parte de los casos con independencia de los grandes medios de comunicación de masas, se estructuran bajo la forma de páginas personales, foros de debate, portales de contrainformación o weblogs. Compiten con los grandes medios en la configuración de la opinión pública, pero no lo hacen con las mismas reglas, sino que 
ofrecen un producto radicalmente distinto, para un público, el propio de las tecnologías digitales, que comienza a diferenciarse del público tradicional de la comunicación de masas:

- Se trata de medios altamente politizados, en muchos casos explícitamente partidistas.

- Su interpretación de la realidad se da en un contexto en el que es evidente, para estos medios y para el propio público, que dicha realidad se configurará cada vez en mayor medida merced a la acción del público, a través de una selección de medios altamente personalizada. La capacidad de selección del público, aunque muy reducida en lo que concierne a la información, se ve considerablemente ampliada en lo tocante a la búsqueda y consumo de interpretaciones y opiniones ligadas a dicha información. En consecuencia, ninguno de estos medios puede aspirar, como sí lo hacían los grandes medios tradicionales, a constituirse en referencia exclusiva de un sector significativo del público. Pero su acción combinada sí está consiguiendo que un sector cada vez más grande del público consumidor de medios configure su opinión a partir de un abanico plural de medios, del que los grandes medios de masas sólo son parte, aunque sea una parte sustancial.

- Finalmente, estos medios, por sus propias características y por las posibilidades que confiere la comunicación digital, establecen abundantes espacios de discusión en los que el público puede adoptar un papel activo, ligados a un texto fuente (como ocurre en los weblogs) o que directamente definen el hecho comunicativo (como sería el caso de los foros de debate).

Naturalmente, los grandes medios de comunicación siguen siendo los referentes fundamentales del gran público, pero ya no son los únicos: y conforme es mayor la implicación del público en determinado asunto de actualidad, y mayor su necesidad de consumir opiniones diferenciadas e incluso participar activamente con su opinión, mayor es el papel de los distintos medios ajenos al flujo de la comunicación de masas.

Hasta la fecha, ha sido precisamente en cuestiones centrales de la actualidad, española e internacional, cuando estos medios han tenido mayor importancia en la configuración de la opinión pública. Dos casos emblemáticos son el movimiento antiguerra de Irak que tuvo lugar en todo el mundo, y con particular incidencia en España, en los meses de Febrero-Abril de 2003 y el frenético consumo de informaciones y opiniones que tuvo lugar en los días que siguieron a los atentados terroristas del 11 de Marzo de 2004 en Madrid.

- La guerra de Irak. el público que siguió la información sobre la II Guerra del Golfo pudo hacerlo a muy variados niveles:

a) En primer lugar, el público pudo acceder, naturalmente, a la información configurada por los grandes medios de comunicación de masas, muy similar en cuanto a los contenidos, pero no tanto en la interpretación de los mismos. La asunción, por parte de los ciudadanos, de un 
interés, y una fuerte implicación, respecto de todo lo relacionado con la invasión de Irak y sus prolegómenos, tuvo una importante incidencia en la política informativa de los grandes medios, que directa o indirectamente tuvieron que posicionarse. En este sentido, durante la guerra se reprodujo el "pluralismo formal" que en otro lugar ${ }^{5}$ hemos identificado como característico de los grandes medios españoles, esto es, una similitud temática que respeta la teoría de la Agenda Setting pero fuertemente matizada por la orientación ideológica con que se ofrecía la información, es decir, la interpretación de la misma. La novedad es que dicho "pluralismo formal" solía darse en acontecimientos de carácter nacional con una fuerte implicación mediática - ciudadana (por ejemplo unas elecciones generales), no en asuntos de carácter internacional.

b) Pero junto a la información habitualmente desplegada por los grandes medios, el público español tuvo acceso a una enorme cantidad de fuentes informativas de carácter más o menos minoritario. Por un lado, la gigantesca diversidad de informaciones suministradas a través de la Red Internet; por otro, la existencia de canales de televisión temáticos, asociados normalmente a las plataformas de TV por satélite o por cable.

Puede discutirse, naturalmente, la incidencia práctica de este tipo de informaciones más o menos secundarias respecto de los grandes medios de comunicación, pero es preciso tener muy en cuenta que su difusión aumentaría considerablemente, aunque fuera de forma indirecta, gracias a un último factor, muy determinante: la existencia de una comunicación de carácter interpersonal que permitía extender con gran velocidad todo lo relacionado con el conflicto, desde las convocatorias de las manifestaciones contrarias a la guerra hasta las últimas novedades en el frente, pasando por la política exterior desarrollada por España a lo largo de toda la crisis.

Posiblemente el porcentaje del público que tuviera acceso a informaciones de carácter minoritario en Internet, o en las televisiones temáticas, fuera muy reducido; sin embargo, su difusión, por la Red (a través del email, por ejemplo) o fuera de ella (mediante el comentario social), fue mucho mayor, gracias fundamentalmente a que se contaba con un público interesado en todo lo referente a este asunto, deseoso, en consecuencia, de consumir todo tipo de informaciones, y comentarlas y debatirlas con su entorno.

Como consecuencia, a través de los medios de masas, de sistemas de comunicación en red (Internet) que permitían acceder a todo tipo de informaciones, de información de carácter más o menos exclusivo

\footnotetext{
${ }^{5}$ Véase el trabajo Comunicación Electoral y Formación de la Opinión Pública: las Elecciones Generales de 2000 en la prensa española", Valencia, Servei de Publicacions de la Universitat de València, 2004. Pude observar la aparición sistemática de este "pluralismo formal" como consecuencia del contraste entre una selección de las informaciones relevantes bastante similar que, sin embargo, eran leídas, o interpretadas, de forma muy distinta en cada uno de los medios de referencia analizados (El País, El Mundo, La Vanguardia y ABC). Cada medio, en cierto sentido, efectuaba una sincronización entre las información y opinión, analizando en las columnas y editoriales lo expuesto en la información, pero también interpretando, de forma bien patente, la información en función de su línea ideológica.
} 
a la que el público podía acceder previo pago (las televisiones temáticas), y sobre todo gracias a su difusión posterior mediante la comunicación interpersonal, no fueron tanto los medios de masas, sino el propio público, quienes configurarían su propio "menú" informativo, plural y personalizado, y por tanto alejado de cualquier tipo de influencia externa determinante (proviniera de los medios o de los Gobiernos). El público interactuó con la información disponible, y no se conformaría ya con una programación, una selección de contenidos acabada, sino que se afanó en configurarla él mismo.

- Los atentados terroristas del 11 de marzo. En este caso, el marco temporal en el que se desarrollaron los acontecimientos fue mucho más breve, y también mucho más intenso. En apenas tres días, el público consumió compulsivamente todo tipo de informaciones, a menudo contradictorias, sobre los atentados pero, sobre todo, en relación con la autoría de los mismos.

Conforme quedaba de manifiesto la insuficiencia de las informaciones proporcionadas por instituciones y medios de comunicación, y a medida que cristalizaban con claridad dos estrategias informativas contrapuestas, relativas a las dos posibles autorías del atentado (el terrorismo independentista de ETA o el terrorismo islamista), el público pasó de informarse a opinar, y a buscar opiniones, sobre los acontecimientos. Un estudio de corte empírico (Sampedro y López, 2005), fundamentado en datos de audiencia $^{6}$, pone de manifiesto con claridad una evolución claramente diferenciada de los medios tradicionales y los pequeños medios de comunicación interpersonal o ajenos a la comunicación de masas, fuertemente politizados, disponibles en Internet.

Los medios de comunicación de masas (prensa, radio, televisión y principales medios digitales) experimentaron un enorme crecimiento de la audiencia el día 11 de Marzo, que en días posteriores iría remitiendo; sin embargo, los pequeños medios digitales, ajenos al flujo de la comunicación de masas (weblogs, foros de debate y medios de contrainformación), aunque su crecimiento inicial, el día 11 de Marzo, fue generalmente de menor calado, continuaron creciendo, y normalmente alcanzarían sus mayores cotas de audiencia el mismo día 14 de Marzo, es decir, el día de las elecciones generales.

La interpretación de estos datos tan divergentes en función de las características del medio parece clara: en situaciones de gran interés por adquirir información, en un contexto en el que los grandes medios de masas, fuente de referencia fundamental, no son capaces de ofrecer una visión de conjunto satisfactoria a un público eminentemente activo, los medios "alternativos" cubren un hueco, el correspondiente a la interpretación, que hace apenas unos años correspondía también a un número reducido de medios de comunicación, complementados en todo caso por el comentario social, que ahora se ve redimensionado por efecto de distintos sistemas de comunicación digital que son muchas veces, de nuevo, sistemas de comunicación interpersonal.

${ }^{6}$ Se comparó los días del 11 al 14 de Marzo con los días correlativos de la semana anterior, es decir, del 4 al 7 de Marzo, recabando datos de audiencias de fuentes diversas, en función de la naturaleza del medio. 


\subsection{El público como prosumidor de información}

El paradigma de la Agenda Setting no presta excesiva atención a las diferencias de tipo ideológico que podemos encontrar en los distintos representantes del ecosistema comunicativo. La teoría se concentra fundamentalmente en dejar constancia de la homogeneidad de este ecosistema en lo que concierne a la selección de informaciones de actualidad. La comunicación digital, caracterizada por la extrema diversidad de medios de comunicación disponibles para el público, no implica hasta la fecha, como hemos visto, cambios significativos respecto del paradigma. La abundancia de medios, normalmente, no se ve correspondida por la abundancia de fuentes, que siguen circunscribiéndose a un número reducido de grandes medios de comunicación y, en particular, agencias de información. Las carencias de este sistema de medios, remitido constantemente no sólo a los mismos asuntos noticiosos, sino a las mismas fuentes, justifica la aparición de multitud de pequeños sistemas de comunicación, tales como los weblogs o los portales de contrainformación, extremadamente politizados, que permiten desarrollar, al menos, un pluralismo en la interpretación de las noticias mucho más sustancioso. Pero estos medios no son normalmente capaces, no tienen la infraestructura necesaria, para complementar a los grandes medios de masas también en la información.

Por ese motivo, el paradigma de la Agenda Setting sigue siendo operativo en lo fundamental: siguen siendo los medios de comunicación de masas los encargados de configurar un escenario de la actualidad que resulte convincente para el público, por más que las interpretaciones derivadas de ese escenario se encuentren cada vez más dispersas. Sin embargo, pese a todas sus insuficiencias, los pequeños medios de comunicación digital, en algunas situaciones muy concretas, sí están desarrollando algunas líneas de ruptura del paradigma, muy incipientes aún, que convendría comentar someramente:

- Del rumor a la noticia. Internet presenta un escenario caracterizado por una sobreabundancia de medios de comunicación circunscritos, a su vez, a un número muy reducido de fuentes informativas. La información elaborada con criterios periodísticos, en este contexto, participa cada vez más claramente del fenómeno de la mcdonalización, al que ya hemos aludido. Al mismo tiempo, la Red facilita considerablemente la edición, publicación y difusión de todo tipo de informaciones, vulnerando muchas veces en el proceso los más elementales criterios periodísticos de producción de noticias: muchas informaciones no están firmadas, algunas informaciones son un plagio de otras fuentes, no están contrastadas o, directamente, son falsas.

Sin embargo, todas ellas han encontrado acomodo en el flujo asistemático y masivo de información que caracteriza a la comunicación digital, y en particular revisten importancia los llamados "confidenciales" de Internet, tales como www.elconfidencial.com, www.hispanidad.com, www.elsemanaldigital.com o www.elconfidencialdigital.com. Todos ellos están dirigidos por reconocidos periodistas españoles, muchas veces colaboradores de medios impresos o audiovisuales de referencia, como es el caso, en los confi- 
denciales citados, de Jesús Cacho, Eulogio López, Antonio Martín Beaumont y José Apezarena, respectivamente.

Aunque los confidenciales de Internet sean evolución de los antecedentes impresos, su funcionamiento es totalmente distinto. La información confidencial se basa exclusivamente en la credibilidad del confidente. Es una información que carece de fuentes reconocibles, con lo que el lector ha de asumir que la apelación del emisor a fuentes sin identificar corresponde a la realidad, dado que no tiene forma de comprobar que en efecto sea así. La información confidencial, en consecuencia, pertenece a la categoría del rumor. El rumor ha funcionado históricamente como un proceso de creación de la opinión pública, ante todo, no formalizado, sin un origen ni un destino concretos, o al menos identificados claramente. El motivo por el que los boletines de información confidencial suponen, en realidad, la antítesis del modelo de creación y transmisión de rumores, es que aquí la información es confidencial pero se ofrece (gratuitamente, además, en los principales confidenciales españoles) al conjunto del espacio público, con lo cual, obviamente, deja de ser confidencial.

Estos peculiares “confidenciales”, que se ofrecen de forma gratuita al gran público, son pasto de informaciones sin confirmar (de hecho, se basan justamente en informaciones sin confirmar), relativas a la actualidad en todos sus planos, ofreciendo al público una información complementaria y diferenciada de la información formalizada de los medios de comunicación de masas. Su amplia difusión supone un quebranto de los criterios de rigor periodístico en el tratamiento de la información, pero también manifiesta el interés del público por acceder a informaciones que se alejan de la norma periodística y, en un segundo estadio, desarrollan una esfera pública donde la información relativa al poder es mucho más porosa e incontrolable, por cuanto puede ser difundida rápidamente al gran público a través de los confidenciales, y también por el hecho de que es el rumor, y no la noticia, el mecanismo de transmisión de informaciones entre el público relativas al poder (Thompson, 2001: 49).

- Del público a los medios. Una de las características principales de la comunicación digital es la interactividad. Interactividad entre el público y la información, entre emisor y receptor, e interactividad entre los individuos que conforman un público activo, singularmente diferenciado del gran público propio de la comunicación de masas. Esta interactividad, desarrollada a diversos niveles, permite al público no sólo comentar e interpretar las informaciones aparecidas en los grandes medios de comunicación, sino responder a las mismas e incluso invalidarlas. La crítica a los contenidos del medio, que en la comunicación de masas revestía un carácter fundamentalmente pasivo, expresado en términos de audiencia (esto es, consumir o no un determinado medio de comunicación dependiendo del grado de satisfacción con sus contenidos), en la comunicación digital puede desarrollarse de muy distintas maneras, y puede hacerse patente a través de la comunicación interpersonal tecnológicamente mediada e incluso mediante los pequeños medios de comunicación generados directamente por el público, tales como los weblogs o los foros de debate. 
La capacidad del público para enmendar la plana a los medios, no sólo criticar los contenidos de éstos, sino generar una respuesta, es también incipiente, pero ya podemos citar, al menos, un ejemplo concreto, en el caso español, muy significativo: la rápida difusión, a través de la Red, de todo tipo de críticas a la campaña publicitaria desarrollada por el diario El País Digital a través del correo electrónico, que tuvo lugar del 13 al 15 de Septiembre de 2004. La promoción publicitaria, titulada "Un día da para mucho", consistía en el anuncio de la siguiente página.

Este anuncio generó hondas repercusiones en el sistema de weblogs españoles, que rápidamente procedieron a publicar el anuncio en sí y todo tipo de comentarios al respecto, generalmente críticas muy negativas. Dos días después del inicio de la campaña, el 15 de Septiembre, el autor del weblog Barcepundit (http://barcepundit.blogspot.com) publica un comentario en la versión en inglés de su weblog, y a partir de ahí, en sólo unas horas, el asunto pasa a ser comentado en gran número de publicaciones estadounidenses, en términos, como cabe imaginarse, aún más negativos. La proliferación de noticias, publicadas primero en medios ajenos al flujo de la comunicación de masas, pero también en diversas cabeceras de referencia estadounidenses, así como las continuas llamadas y escritos de protesta a la redacción del diario El País (e incluso a las embajadas españolas en EE.UU. y otros países) obligó al periódico, el mismo día 16 de Septiembre, no sólo a retirar la campaña, sino a pedir disculpas en su página editorial y en la propia primera de El País.

- El público como emisor de información. Finalmente, la comunicación digital facilita que el público pueda asumir, en situaciones hasta la fecha muy concretas, la función de emisor de informaciones diferenciadas. Las facilidades de publicación, la instantaneidad y la portabilidad de las tecnologías digitales posibilitan la conformación de un público que no sólo es activo en la selección de informaciones y opiniones y en la participación en diversos espacios de discusión, sino que también puede generar sus propias informaciones para consumo general. En la mayor parte de los casos, las informaciones generadas por el público pertenecen a un espacio enormemente especializado, y están dirigidas a un público también muy concreto. Muchos weblogs, por ejemplo, funcionan como "diario" personal del autor, que publica en la Red sus vivencias para compartirlas con sus lectores.

Es evidente que en este ámbito los sistemas de comunicación ajenos al flujo de la comunicación de masas no compiten con los grandes medios, puesto que elaboran noticias que de todos modos serían sin duda desechadas por las publicaciones periodísticas; se trata, en todo caso, de una información complementaria, perteneciente, al igual que los medios que la albergan, a un ámbito ajeno al foco de la actualidad, que seguiría siendo definida por los medios de comunicación de masas.

Sin embargo, ¿qué ocurre cuando las vivencias del público sí que tienen un interés objetivo en la conformación de la actualidad? En ese caso, las informaciones publicadas en estos medios no sólo serían un complemento interesante para las informaciones estandarizadas y formalizadas de los grandes medios 


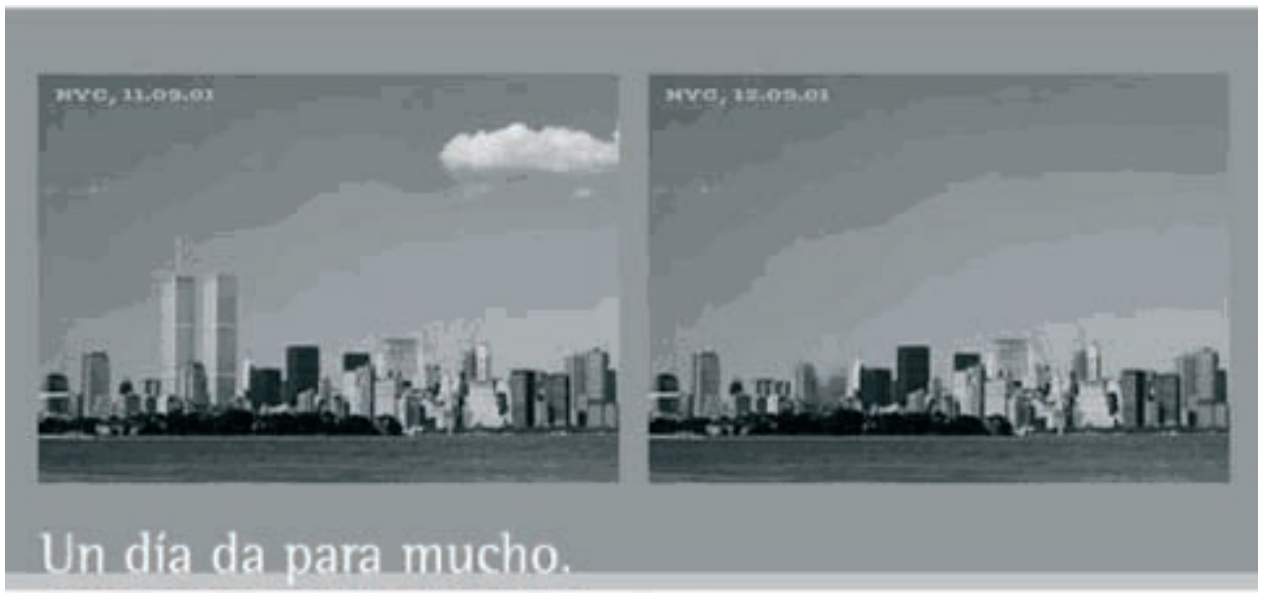

Imaginese lo que puede suceder en tres meses.

Ahora, si se suscribe a ELPAIS.es antes del 8 de Oetubre, le regalamos bes meses gratis.

En ELPAIS.es encontrará toda la actualidad al minuto, información analizada desde todas las perspectivas, noticias de última hora, más de 1.300.000 artículos publicados desdo 1976, animaciones multimedia exdusivas y algunas de las mejores fimas de nuestro pais.

Suscribase ahora a EL. PAIS.es y disfrute de 3 meses de noticias gratis.

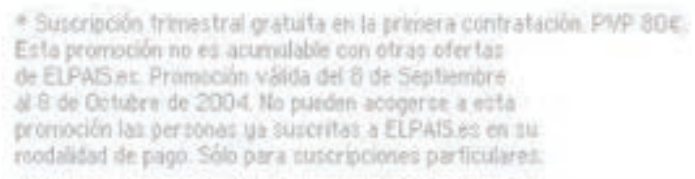

\section{EL PAIS.es}

Entre en ef dub de los meior infermades

\begin{tabular}{|c|c|}
\hline $\begin{array}{l}\text { Para acceder a su cuents canalmail, } \\
\text { modificar sus datos o borrarse } \\
\text { del servicio pulse squi }\end{array}$ & $\begin{array}{c}\text { Gracias por confiar en } \\
\text { /elPeriódico }\end{array}$ \\
\hline
\end{tabular}

From: Canalmail [mailto:canalmail.2850.2659299@canalmail.com]

Sent: Tuesday, September 14, 2004 2:09 PM

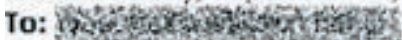

Subject: ELAIS.es: Entre en el club de los mejor informados

Fuente: weblog de Arcadi Espada (http://www.arcadi.espasa.com), el 15 de Septiembre de 2004. 
de comunicación, sino que claramente permitirían cubrir un hueco, el abandonado por dichos medios, incapaces de satisfacer con la rapidez y efectividad necesarias (por falta de recursos económicos y logísticos o por simple desinterés) la demanda de información del público.

El ejemplo más famoso de cómo el público puede constituirse en fuente informativa es el del weblog "Salam Pax" (dear_raed.blogspot.com, actualmente inactivo), escrito por un joven arquitecto iraquí residente en Bagdad durante los prolegómenos de la II Guerra del Golfo y a lo largo del conflicto. Este weblog, publicado en inglés, vehículo de expresión de las vivencias de su autor a lo largo de estos meses cruciales, en los que Bagdad fue uno de los centros informativos del planeta, permitía que el gran público accediera a una información de enorme valor, precisamente por tratarse de una información que los grandes medios no podían proporcionar: la de los testigos del acontecimiento (la II Guerra del Golfo), sin intermediación periodística. El éxito del weblog fue tal que, para asegurar su difusión, se crearon réplicas de sus contenidos en múltiples espacios de la WWW. Su autor fue contratado por el diario The Guardian como columnista, y los contenidos del weblog acabaron publicándose bajo la forma de libro ${ }^{7}$.

El ejemplo de Salam Pax es el más conocido, pero no el único, de la transmisión de todo tipo de informaciones por parte de los protagonistas de las mismas, a través de su propio medio de comunicación. El conflicto de Irak ha sido enormemente fructífero al respecto, con aportaciones de los invasores (por ejemplo, el weblog colectivo "Sgt. Stryker: The Daily Brief", http://www.sgtstryker.com/), los invadidos (como el weblog "Baghdad Burning”, http://riverbendblog.blogspot.com/, obra de una mujer iraquí) y los propios periodistas desplazados a Irak, como el weblog "Kevin Sites" (http://www.kevinsites.net), obra de un reportero freelance que funciona como "una unidad móvil de una persona que utiliza la tecnología digital para recoger, escribir, editar y transmitir noticias relativas a las áreas de conflicto de cualquier parte del mundo"s.

En el caso español, el uso de las tecnologías digitales para emitir informaciones diferenciadas en este tipo de medios no ha alcanzado la misma importancia, pero, y de nuevo en situaciones de gran interés por adquirir información por parte del público, ya encontramos acontecimientos registrados directamente por sus protagonistas, ajenos total o momentáneamente (en el caso de los periodistas) a la estructura de un medio de comunicación de masas. El caso del weblog escolar.net, obra del periodista de Informativos Telecinco Ignacio Escolar, en relación a los atentados terroristas del 11 de Marzo en Madrid y los acontecimientos posteriores, es ilustrativo. Ignacio Escolar publicó en su weblog todo tipo de informaciones provenientes de los grandes medios de comunicación, referidas a los atentados y a la autoría de los mismos, ejerciendo como gatekeeper para sus lectores, y el día 13 de Marzo se constituyó él mismo en fuente de la información al asistir a la concentración frente a la sede del PP en la calle

\footnotetext{
7 Existe versión española: Salam Pax. El internauta de Bagdad. Barcelona, Mondadori, 2003.

${ }^{8}$ En http://www.kevinsites.net/bio.php.
} 
Génova de Madrid y transmitir, directamente desde el lugar del acontecimiento, informaciones que quedaban instantáneamente publicadas en su weblog.

Bien es cierto que en situaciones de "normalidad" el papel de los medios ajenos al flujo de la comunicación de masas suele ser mucho más modesto, circunscribiéndose a la selección de informaciones de los grandes medios y su interpretación posterior, de la que suelen participar directamente los lectores. Pero la existencia de lo que Howard Rheingold (2004) denomina "multitudes inteligentes", es decir, la presencia activa de los ciudadanos, pertrechados de sus dispositivos digitales conectados a la Red, mediante los cuales la publicación y difusión de todo tipo de informaciones queda considerablemente simplificada, es un factor de enorme importancia en la consideración de un ecosistema comunicativo en el que la dependencia del público respecto de los grandes medios se reduce cada vez más, desde luego en la interpretación de la realidad, pero también, en ocasiones, en la propia configuración de la misma9.

\section{Conclusiones}

Una somera revisión a los múltiples medios de comunicación surgidos en la Red, así como a las demás manifestaciones de la comunicación digital, pone de manifiesto en qué medida dichos medios, fundamentándose en las mismas fuentes informativas que los grandes medios de comunicación, e incluso asumiéndolos a éstos como fuente, elaboran análisis y opiniones extraordinariamente variados, mucho más fecundos, en cuanto al pluralismo que alumbran, que la clásica sincronización entre opiniones e informaciones tan propia de los grandes medios. El público, haciendo uso de su capacidad de selección, y aunque dicha capacidad se vea singularmente relativizada por la mimetización de los mismos contenidos informativos, una y otra vez, en los medios que acogen estos contenidos, sí consigue elaborar un menú "interpretativo" de la realidad mucho más variado y, sobre todo, personalizado en función de sus intereses.

Si tomamos como referencia una de las noticias analizadas, la comparecencia de José María Aznar ante la Comisión parlamentaria del $11 \mathrm{M}$, la interpretación de la misma ya no sólo se produce en los editoriales, artículos de opinión o tertulias ubicados en los grandes medios de comunicación de masas,

\footnotetext{
${ }^{9}$ El potencial de las “multitudes inteligentes" para redefinir la propia práctica del periodismo se antoja ingente: “ $i$ Y si las multitudes inteligentes llegasen a generalizar la práctica del periodismo no profesional p2p entre usuarios corrientes? Imaginemos la tremenda repercusión del vídeo de Rodney King multiplicada por el poder popular de Napster. ¿Y si la gente transmitiese vídeo WearComp a la web, ofreciendo imágenes continuas de noticias de última hora que hasta el momento sólo eran accesibles a través de NewsCorp, AOL-Time-Warner y Disney? ¿Sería posible invertir las tornas de la sociedad de la vigilancia y contrarrestar los monopolios mediáticos? ¿Cuáles serían los efectos sobre la opinión pública si miles de ciudadanos provistos de WearComp enviasen a la red todo lo que ven y oyen? Por descabellado que parezca, ya han aparecido bandas móviles de teleperiodistas ciudadanos. Todavía está por ver si los experimentos actuales interferirán con el radar de los gigantes mediáticos, pero los primeros indicios del periodismo p2p se detectan ya". (2004: 194)
} 
que inevitablemente, y en pura lógica, tienden a confirmar la línea ideológica que define al medio (de ahí la referencia a la sincronización entre informaciones y opiniones a la que hemos aludido). Además, la interpretación de las declaraciones del ex presidente del Gobierno se desarrolla también en un número indeterminado de medios de comunicación en red, tales como cuadernos de bitácora, páginas de contrainformación, espacios de debate y opinión, etc., que complementan y en ocasiones sustituyen la preponderancia interpretativa de los medios tradicionales. Por último, el público activo, capaz de seleccionar en alto grado sus preferencias en la configuración de la actualidad mediática, también puede hacer uso del comentario social para proceder a una interpretación de los datos proporcionados por los grandes medios. El comentario social, segundo eslabón de una transmisión de la actualidad centralizada por los medios de comunicación de masas, encargados de indicar al público cuáles son los asuntos de actualidad (Gomis, 1991), se ve ahora considerablemente potenciado merced a la emergencia de múltiples formas de comunicación interpersonal tecnológicamente mediadas (tales como el correo electrónico, los foros de debate, los chats, los distintos mecanismos de comunicación que posibilita la telefonía móvil, etc.), que complementan y potencian la tradicional comunicación cara-a-cara.

Esta enorme abundancia de fuentes de opinión e interpretación de la realidad contrasta vivamente con el predominio de una información estandarizada según criterios periodísticos, que sigue siendo en gran medida privativa de un número reducido de grandes medios de comunicación (dependientes, a su vez, de un número aún más reducido de agencias de información y fuentes institucionales). El pluralismo interpretativo no supone, en principio, una superación del paradigma de la Agenda Setting, pero sí una importante reformulación: los grandes medios siguen siendo importantes por indicar al público no qué pensar, sino sobre qué pensar. Sin embargo, en un contexto en el que la capacidad de los medios para indicar al público qué pensar sobre aquello que ocupa el escenario de la actualidad periodística no hace más que reducirse, puesto que caen en un modelo de periodismo aséptico derivado de informaciones de agencia, es cada vez más importante, y así lo manifiesta el nuevo público de la comunicación en red, usuario activo de gran número de medios, satisfacer la necesidad de obtener una interpretación y análisis plausibles de esa realidad. Y este segundo elemento, la generación de interpretaciones y opiniones a partir de las noticias, cada vez se aleja más del dominio de los grandes medios de comunicación ${ }^{10}$.

${ }^{10}$ Siguiendo a Maxwell McCombs, podemos considerar que "hay dos aspectos de la influencia de los medios informativos en la fijación de la agenda temática. A partir del modelo de cobertura informativa total, la relación de objetos que los medios incluyen en su agenda temática, el público aprende cuáles son los asuntos importantes y quiénes son los personajes públicos más destacados del día. A partir de los detalles de esta cobertura informativa -la relación de atributos presentados por los medios informativosel público se forma sus imágenes y sus opiniones sobre estos asuntos y estos personajes públicos. Estos efectos de fijación de la agenda temática constituyen medidas de éxito en dos pasos iniciales del proceso de comunicación, atraer la atención del público hacia un tema y enseñar al público detalles pertinentes sobre dicho tema" (2004). El primer elemento de fijación sigue siendo privativo, con alguna excepción hasta la fecha poco habitual, de los grandes medios. Pero el segundo, la formación de opiniones, aunque parta de los asuntos marcados por los medios de comunicación de masas, ya no deriva en la misma medida de la interpretación esbozada por éstos, puesto que es el propio público el que, como "prosumidor" de informaciones, se encarga de reelaborar los datos para adecuarlos a su visión del mundo, compartida con el entorno con el que intercambia opiniones. 
El pluralismo informativo quedaría subsumido en un "pluralismo opinativo", que explicaría en parte el éxito de público de los medios más politizados, frente a la información aséptica proveniente de las agencias. En efecto, ni los weblogs, ni los medios de contrainformación, ni mucho menos las distintas formas de comunicación interpersonal son ejemplo de objetividad periodística, sino, bien al contrario, sintomáticos de la politización cada vez más elevada de la información, y de la confusión de dichas informaciones con el trasunto ideológico que las conforma y en función del cual se presentan ante el público. Son ejemplos de esta tendencia el éxito de los confidenciales de Internet o de publicaciones de carácter casi propagandístico, como Libertad Digital. En Libertad Digital las informaciones de agencia se combinan directamente con interpretaciones enormemente politizadas, asociadas a la ideología neoliberal de este medio, que forman parte de las propias noticias y se ven extendidas y complementadas por una enorme profusión de artículos de opinión que componen la "oferta interpretativa", e incluso "ideológica", de este medio.

La emergencia de éstos y otros medios de comunicación digital, alejados de las reglas clásicas de generación de contenidos propias de los grandes medios de comunicación de masas, sí puede suponer la emergencia de algunas líneas de fractura, aún incipientes, en el paradigma de la Agenda Setting. Dicho modelo, insistimos, se fundamentaba en un sistema jerárquico y unidireccional de transmisión de informaciones, donde un número reducido de medios de comunicación, con contenidos estructurados según criterios profesionales de producción, se constituía en fuente fundamental de explicación del mundo para un público de carácter pasivo. Este modelo es el que sigue explicando la generación de contenidos en los medios de comunicación de masas, tal y como hemos visto en el análisis de noticias de actualidad efectuado en el apartado 2.

Sin embargo, en un contexto en el que estos medios de masas ofrecen un producto que proviene reiteradamente de las mismas fuentes (las agencias de información) y que apenas presenta reelaboración periodística más allá de la mera reproducción, y además se dirigen a un público activo, caracterizado por a) su capacidad de selección entre un número ingente de medios, muchos de ellos ajenos a estas rutinas productivas; b) el desarrollo de múltiples mecanismos de interactividad entre el público y el medio, y singularmente entre los miembros del público; y c) la eventual conversión del público en emisor de la información, el flujo de la información experimenta importantes cambios (Bowman y Willis, 2003: 13). El público ya no se limita a recibir informaciones preconfiguradas por los medios, y a lo sumo comentarlas posteriormente: la interpretación de los hechos, privativa de los grandes medios en el escenario anterior, está ahora, cuando menos, compartida con el público y con los medios ajenos al flujo de la comunicación de masas generados por el propio público. La generación de informaciones, por último, aunque sigue proveniendo fundamentalmente del ámbito del periodismo profesional, también puede darse a partir de los medios de comunicación "alternativos", esto es, weblogs, portales de contrainformación e incluso espacios de debate desarrollados en la Red. Este ecosistema comunicativo, mucho más plural, asistemático e incontrolable que el anterior, puesto que el número de medios aumenta exponencialmente conforme lo 
hace también la implicación del público, funciona por ahora en toda su extensión a propósito de acontecimientos de gran impacto en el público, y sigue estando circunscrito en la práctica a un sector aún minoritario de la población (Mazzoleni, 2004: 280-281), pero parece en cualquier caso indudable que la incidencia de los muy diversos medios que englobamos dentro de la denominación de "ajenos al flujo de la comunicación de masas" no hará sino aumentar en el futuro.

\section{Referencias bibliográficas}

- Bowman, S., Willis, C. (2003). We Media. How audiences are shaping the future of news and information. Disponible en http://www.hypergene.net/wemedia/download/we_media.pdf.

- Dader, J.L. (1990). "Las provincias periodísticas de la realidad". Comunicación y Sociedad, Vol. III, núms. 1 y 2, pp. 85-134

- Dader, J. L. (1992). El periodista en el espacio público. Barcelona: Bosch.

- Gomis, L. (1991). Teoría del periodismo. Cómo se forma el presente. Barcelona: Paidós.

- Igartua, J.J., Humanes, M.L. (2004). Teoría e investigación en comunicación social. Madrid: Síntesis.

- López, G. (2004). Comunicación electoral y formación de la opinión pública. Las Elecciones Generales de 2000 en la prensa española. Valencia: Servei de Publicacions de la Universitat de València.

- López-Escobar, E., Llamas, J. P., y McCombs, M. (1996). "Una dimensión social de los efectos de los medios de difusión: agenda-setting y consenso". Comunicación y sociedad, Vol. IX, núms. 1 y 2, pp. 91-125.

- Mazzoleni, G. (2004). La comunicazione politica. Bolonia: Il Mulino.

- McCombs, M. (2004). "Información relevante para sociedades democráticas. Llegar efectivamente al público”. Telos n. ${ }^{\circ}$ 58, Enero-Marzo 2004. Disponible en http://www.uv.es/demopode/debates/comunicacionred/McCombsesp.pdf.

- Rheingold, H. (2004). Multitudes inteligentes. La próxima revolución social. Barcelona: Gedisa.

- Ritzer, G. (1996). La McDonalización de la sociedad. Un análisis de la racionalización en la vida cotidiana. Barcelona: Ariel.

- Sampedro, V., López, G. (2005). "Deliberación celérica desde la periferia”, en Sampedro, V. (Ed.), 13-M: Multitudes on line. Madrid: Libros de La Catarata, pp. 119-158.

- Thompson, J.B. (2001). El escándalo político. Barcelona: Paidós.

- Valiente, F. J. (2004). “Comunidades virtuales en el ciberespacio”. doxa comunicación, vol. 2, pp. 137-150. 